\title{
Hydrocephalus in the Pediatric Population in the Tropic Co-morbidity Impact at CHU in Conakry
}

\author{
Ibrahima Sory Souare $^{1}$, Luc Kezely Beavogui ${ }^{1}$, Alpha Boubacar Bah ${ }^{1}$, Soriba Naby Camara ${ }^{2}$, \\ Ange Castilla Mekoulou ${ }^{1}$, Daniel Tama Bobane ${ }^{1}$, Moussa Conde ${ }^{3}$, Naby Daouda Camara ${ }^{4}$, \\ Amara Cisse ${ }^{5}$ \\ ${ }^{1}$ Department of Neuro Surgery, University Gamal Abdel Nasser of Conakry, Conakry Guinea \\ ${ }^{2}$ Department of Pancreatic Surgery, Huazhong University of Science and Technology, Wuhan, China \\ ${ }^{3}$ Department of Pediatric Surgery, University Gamal Abdel Nasser of Conakry, Conakry, Guinea \\ ${ }^{4}$ Department of General Surgery, University Gamal Abdel Nasser of Conakry, Conakry, Guinea \\ ${ }^{5}$ Department of Neurology, University Gamal Abdel Nasser of Conakry, Conakry, Guinea
}

Email address:

Souare.is@yahoo.fr (I. S. Souare), csoribanaby@yahoo.com (S. N. Camara)

\section{To cite this article:}

Ibrahima Sory Souare, Luc Kezely Beavogui, Alpha Boubacar Bah, Soriba Naby Camara, Ange Castilla Mekoulou, Daniel Tama Bobane, Moussa Conde, Naby Daouda Camara, Amara Cisse. Hydrocephalus in the Pediatric Population in the Tropic Co-morbidity Impact at CHU in Conakry. American Journal of Psychiatry and Neuroscience. Vol. 4, No. 4, 2016, pp. 65-70. doi: 10.11648/j.ajpn.20160404.12

Received: June 19, 2016; Accepted: June 27, 2016; Published: July 18, 2016

\begin{abstract}
Hydrocephalus is a pathologic dilatation of the ventricles which occurs progressively when provoked by a disruption in the production, circulation and reabsorption of the cerebrospinal fluid (CSF). This study aims to report the impact of co-morbidities on the surgical outcome of pediatric hydrocephalus in Guinea. It was a retrospective clinical study carried out at Friendship hospital, Sino-Guinea of Kipe, for 13 months. 107 patients were scheduled for hydrocephalus surgery. The incidence of Hydrocephalus was $8.20 \%$ related to the 107 patients admitted during our period of study. The main comorbitdies encounter were, anemia ( 73 cases), respiratory infection (38 cases) malaria (malaria 37 cases), malnutrition (14 cases), deshydratation (11 cases), candidosis ( 7 cases), respiratory detress (6 cases), cutaneous infections (6 cases), convulsion (6 cases), meningitis (5 cases), otorhinolaryngology infection ( 2 cases), septicemia ( 2 cases) tardive neonatal infection (91 cases). The outcome of pediatric hydrocephalus, including surgical complications, neurological sequelae and academic achievement, has been the matter of many studies. However, much uncertainty remains, regarding the very long-term and social outcome, and the determinants of complications and clinical outcome. Hydrocephalus is a commonly encountered pediatric pathology in sub-Saharan Africa where it constitutes a major public health concern. The etiologies are still dominated by neonatal infections. The treatment is essentially a surgical approach.
\end{abstract}

Keywords: Hydrocephalus, Co-morbidities, Impact, Pediatric Population, Population in the Tropic

\section{Introduction}

Hydrocephalus is a pathologic dilatation of the ventricles, which occurs progressively when provoked by a disruption in the production, circulation and reabsorption of the cerebrospinal fluid (CSF) [1].

In the infant, it can occur at any age and may originate from a malformation, or post hemorrhagic process during the neonatal period, or following an episode of meningitis in the breastfeeding infant; or due a tumor obstruction in a toddler [2].
Pediatric hydrocephalus (HC) is a surgical disease. If left untreated, most cases are lethal. With present-day Standard of care, most patients with $\mathrm{HC}$ will survive; however, death from hydrocephalus largely prevails even today, and the sequelae among long-term survivors are frequent and often severe [3]. Because of the multiplicity of causes of hydrocephalus, associated diseases, complications of treatment, and the inherent complexity of the patient population, reliable data on outcomes are difficult to obtain. The outcome of hydrocephalic patients has been the subject of many studies, some presenting conflicting results, and 
many focusing on a limited view of this vast field

Shunt failure can be aseptic (malfunction) or septic (shunt infection). Malfunction includes obstruction, over drainage, under drainage, and occult shunt failure (including the need for elective revision for tube lengthening).

Its occurrence being duration-dependent, the incidence of malfunction is generally expressed as actuarial survival. Reoperation, although potentially subject to surgeon bias, can be seen as the best criterion to define malfunction, as it is a binary variable and a dated event, allowing survival analysis Different types of infection rates can be calculated and should be clearly specified: by operation (number of operations complicated by infection); by patient (number of patients in a series having had at least one septic episode); by surgeon (number of septic complications among the total number of patients operated by a given surgeon), or by hospital [4] and actuarial incidence. Rates by surgeon or by hospital can be difficult to ascertain because patients are often operated by different surgeons or in different hospitals [5].

In order to identify the principal pathologies, which are most commonly associated with hydrocephalus for planning management, we have conducted a retrospective study over a period of 13 months by selecting cases encountered and treated in the Neurosurgical department of Friendship Hospital SinoGuinean in Kipe. Consequently, we have proceeded with a review of African literature and compared with similar studies that provide information on the impact of comorbidities on the surgical outcome of pediatric hydrocephalus.

\section{Methodology}

\subsection{Patients}

It is a descriptive retrospective study conducted in the Neurosurgical department of friendship hospital Sino-guinea in Kipe. 107 hospitalized cases of diagnosed hydrocephalus were collected over a period of 13 months.

\subsection{Co-morbidities Assessment}

Evaluation of co morbidities was carried out by investigating antecedent medical history and surgical history separately.

(1). Medical Antecedent

(2). Surgical Antecedent

\subsection{Epidemiological Data Analysis}

Epidemiological parameters including, age, sex, clinical data (reason for seeking medical consult, past medical history, physical signs and symptoms, degrees of macrocephaly, significant co morbidities), paraclinical evaluations, therapeutic management and post-operative follow up.

\subsection{Statistical Analysis}

Statistical analysis was performed using SPSS version 12.0 software, and Student t-test to display the link among the variables in this study. $P$ value smaller than 0.05 was considered statistically significant.

\section{Results}

In our study, the incidence of hydrocephalus has been found to be $8.20 \%$ related to 107 patients who were admitted during our period of study.

The study was carried out on 54 males and 53 female pediatric patients at a sex ratio of 1.01:1. Average age was 8 years old with extremes of 0 to 15 years.

On admission, $83.17 \%$ of our patients were carriers of associated pathologies, against $16.83 \%$ without any, and apathetic (14.9\%).

The main co-morbidities encountered were anemia (73 cases), respiratory infection 38 cases, malaria, 37 cases, malnutrition 14 cases, dehydration 11 cases, candidiasis 7 cases, respiratory distress 6 cases, cutaneous infections 6 cases), convulsion 6 cases, meningitis 5 cases, otorhinolaryngology infection 2 cases, septicemia 2 cases tardive neonatal infection 1 case.

Table 1. Distribution of cases according to antecedent history.

\begin{tabular}{lll}
\hline Antecedent history & Number of cases & $\%$ \\
\hline Medical & 29 & \\
Malaria & 12 & 11.21 \\
Meningitis & 4 & 3.74 \\
Seizures & 4 & 3.74 \\
Respiratory Infections & 4 & 3.74 \\
Malnutrition/Dehydratation & 3 & \\
Others (conjunctivitis, colitis) & 2 & \\
Surgical & 42 & 23.88 \\
DVP & 16 & 23.88 \\
Treated for Spina bifida & 16 & \\
VCS & 5 & \\
Treated for Club foot & 5 & \\
\hline
\end{tabular}

Table 2. CT scan results.

\begin{tabular}{lll}
\hline CT scan results & effectiveness & \% \\
\hline H3V & 47 & 43.92 \\
H4V & 32 & 29.91 \\
H2V & 12 & 11.21 \\
Hydranencephaly & 7 & 6.54 \\
Hydrocephalus withseptation & 6 & 5.61 \\
Extreme hydrocephalus & 3 & 2.8 \\
Other associated lesions & & \\
Dandy Walker syndrome & 14 & 13.08 \\
Encephalomalacia & 8 & 7.48 \\
Intra parenchymal abscess & 3 & 2.8 \\
Encephalocele & 2 & 1.86 \\
Arachnoid cyst & 1 & 0.93 \\
Cyst neoformation & 1 & 0.93 \\
Neoformation of $4^{\text {th }}$ ventricle & 1 & 0.93 \\
Hydroma & 1 & 0.93 \\
\hline
\end{tabular}

The liquid was clear and transparent in 38 cases, purulent in 5 cases, turbid in 6 cases, bloodying 15 cases. 


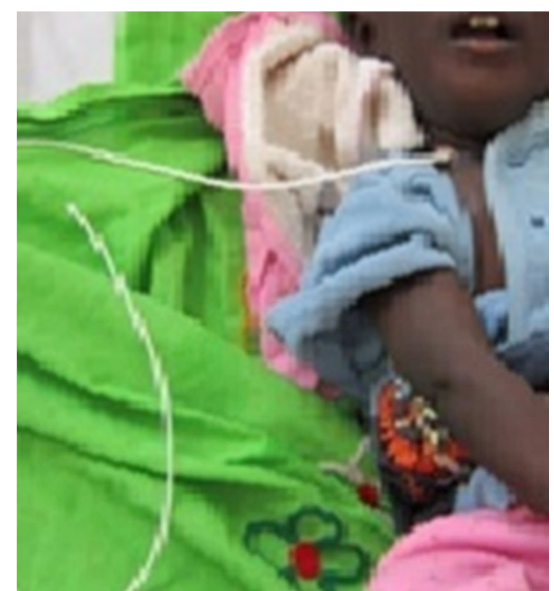

Fig. 1. Year old infant presenting with abdomen Hydrocephalus.

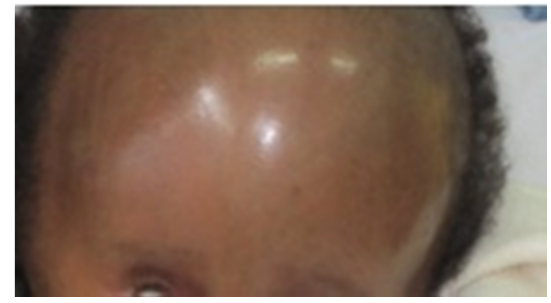

Fig. 2. Child with massive catherization issue, complicated with ascabiosis.

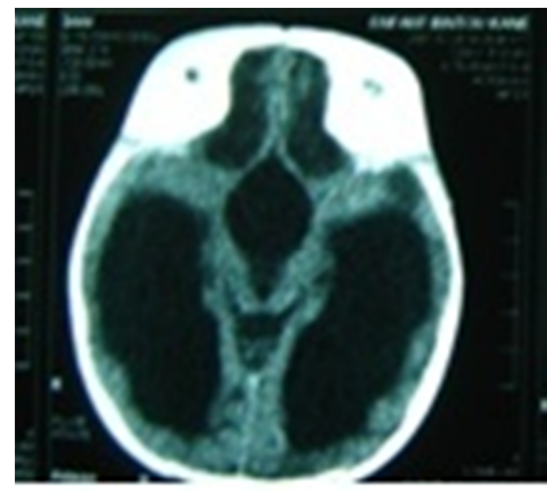

Fig. 3. CT scan putting into evidence the fluid in the lateral ventricles in an infant with hydrocephalus.

\section{Discussion}

WHO estimated the incidence of hydrocephalus to be 3-4 for every 1000 births in the world. In the countries with substandard medical care, $70 \%$ of children remain untreated. The mortality rate in the patients following treatment was noted to be $17 \%$, mostly occurring after the first 2 years of life. General management of hydrocephalus in infants, it is primordial to identify associated pathologies and their impact in the evolution of the conditions in these particular patients.

One of the most crucial factors related to worsening conditions is the regularity of complications arising due to a primitive disease or due to interposed pathology. The postoperative complications linked to shunts also intervene in a notable manner [6].

In Africa, the incidence of post meningitic hydrocephalus varies by country (30\%), 54\% in Ivory coast, $28 \%$ in Nigeria
[15, 16, 17, 18]. In Ouagadougou in 2006, a study showed that hydrocephalus cases related to infectious causes was $43.4 \%$ of which $26.4 \%$ due to meningitis, $15 \%$ due to septicemia, and $1.9 \%$ due to malaria [19]

In 2012 in Guinea, a study on the management of hydrocephalus in children revealed that the most common associated pathologies in their patients were malaria (33.2\%), buccal candidiasis (24.9\%) and bronchopneumonia (24.9\%) [32].

We have thus collected $107(37.8 \%)$ cases linked to hydrocephalus out of a total of 291 patients in our department over 13 months. This proportion is considered relatively elevated, especially, in relation to the free-of-charge treatment offered by the hospital, encouraging more patients to accept treatment. In the majority of cases $(83.2 \%)$, hydrocephalus was found to be linked to pathology.

The most affected age group was between 1-11 months $(74.76 \%)$ with extremes of 12 days to 8 years, at a sex ratio of 1.91 . The average age was estimated at 8.3 months. In a study on 37 patients in Spain in 2005, Castro-Gago M. found that the average age was 8.4 months, at a sex ratio of 1.33 [31]. In 2009 in Mali, Sylla A. had a lower average age of 4 months however, at a higher sex ratio of 1.82 [32]. In 2012 in Morocco, Zouaghi A [33]. also reported a low age average of 3.66 months but low sex ratio of 0.70 . We have not registered any significant difference between the two sexes in terms of incidence.

The increase in cranial volume was noted to be the primary reason for seeking medical consult in 88 cases $(69.1 \%)$, followed by bulging fontanel (21.4\%), fever (15.9\%), weight loss $(13.8 \%)$, cough $(11.2 \%)$. Macrocephaly prevails as the principal sign for seeking medical consult in the majority of reported studies; Sylla A [32] in 2009; Sidibé N [15] in 2012. History taking helped to reveal the preceding symptoms which have contributed to the development of macrocephaly. This finding partly explains the delay in admission.

The delay in diagnosis is marked by socioeconomic and cultural factors which dominate the choice for seeking less conventional methods of treatment.

29 cases were found to be have a history of infectious pathologies; malaria $(11.2 \%)$, meningitis $(3.74 \%)$, seizures $(3.74 \%)$, respiratory tract infections (3.74\%). Surgical interventions predominantly consisted of 16 cases of DVP, 11 cases of cure of meningocele, 5 cases of VCS.

Macrocephaly and bulging anterior fontanel, had been confirmed by physical examination in $90.72 \%$ and $64.48 \%$ of patients respectively. In close to $50 \%$ of cases, sunset eye sign was observed, in one third of cases symptoms related to pathologies were noted: palor of integuments $(42.05 \%)$, rales $(2.29 \%)$, malnutrition $(13.08 \%)$ and cutaneous lesions $(2.8 \%)$.

Kanikomo et Coll [29] had also noted a majority of cases with macrocephaly $(86.5 \%)$, higher percentage of sun setting eye phenomenon $(71.25 \%)$, and bulging anterior fontanel $(69.23 \%)$ in a total of 80 patients.

Zouaghi A. [33] obtained a lower incidence of $57.68 \%$ for macrocephaly, sunset eye sign in $38.5 \%$, and $5.12 \%$ for seizures. 
Analysis of head parameters on admission revealed that over $50 \%$ of cases (29 cases) had minimal macrocephaly $(1-5 \mathrm{~cm})$, or of mild degree $(6-1 \mathrm{~cm})$. In a lesser proportion, we registered a moderate macrocephaly of $10-15 \mathrm{~cm}(17.5 \%)$, and 19 cases with high degree of macrocephaly of $16 \mathrm{~cm}$ or more.

It is necessary to highlight that in this series, only 9 patients admitted had normal cranial circumferences, implying a premature admission. It signifies that the first obvious sign of bulging fontanel is rarely the only motive for seeking appropriate treatment. At any degree of cranial circumference distention, macrocephaly remains a crucial factor to urge parents of patients to obtain consultation.

CT of the cerebral ventricles was considered as a key diagnostic element. It was performed in all admitted patients and allowed us to identify that $44 \%$ had a hydrocephalus involving the lateral and $3^{\text {rd }}$ ventricles simultaneously. Quadriventricular hydrocephalus is the most commonly seen form as described by Tapsoba et Coll [113]; BA M. C. et Coll [12]; Adjenou k. et Coll [27].

In some rare cases, hydranencephaly $(6.54 \%)$ and extreme hydrocephalus $(2.8 \%)$ have been reported. In Cameroon, the proportion of malformation-related hydrocephalus was as high as $60 \%$ [1].

Other African authors [22] have equally mentioned the co morbidities linked to malaria and respiratory diseases which affect both vital prognosis and functionality.

Other congenital anomalies of the brain have been evidenced by the use of $\mathrm{CT}$ with a net predominance of Dandy Walker cyst (13.88\%). Anomalies revealing infections of the nervous systems were uncommon but not rare with observed cases of encephalomalacia (7.48\%) and intraparenchymal abscess $(2.8 \%)$.

Tapsoba et Coll [13] have reported presence of lesions such as acquired aqueductal stenosis in $60.37 \%$ against $37.73 \%$ in congenital cases with superposing infections (43.4\%), malformations (37.7\%) and tumors (13.2\%).

In the series led by de Kanikomo et Coll [29], the incidence of congenital hydrocephalus was higher (62.62\%), infections linked to hydrocephalus, most post-menignitic in nature at $27.69 \%$, tumor-linked in 2 cases.

It is critical to note that consanguine marriage is still widely practiced in present day, and favors the hgh risk of congenital hydrocephalus related to malformations.

The reluctance observed in pregnant women to obtain prenatal care at health centers renders difficult the strategy of providing folic acid supplementation, and therefore, entails a higher rate of malformations.

The lack of regular post natal follow ups contributes to the development of acquired pathologies. Consequently, co morbidities present at admission were as high as $83.77 \%$, with anemia predominating (68.22\%), followed by respiratory infections (30.84\%), malaria (25.23\%), malnutrition (13.08\%), and dehydration $(10.23 \%)$.

Pediatric patients in the age range of 0-24 months were the most affected by these diseases, with the majority between 111 months of age. This age range correlates not only with the most represented age group but also with the lack of environmental and provision of pediatric health care.

Improvement was observed in more than two thirds of cases which initially presented with anemia (76.7\%), respiratory infections $(72.2 \%)$, and malaria $(70.4 \%)$. However, we still reported a mortality rate of $33.3 \%$ in cases with seizures, $25 \%$ in dehydration, and $22.2 \%$ in malaria. It should be specified that a late neonatal infection is linked to a more severe presentation, whereas respiratory distress or septicemia are both fatal in $100 \%$ of cases.

Surgery had been performed in 96 patients (89.7\%), with an average delay of 4.7 days, while in more than two-thirds (17 cases) of patients who presented with 1-3 pathologies, had a delay of 6-11 days.

Despite contraindications overlying the associated pathologies, it was concluded to be more beneficial for the patient to undergo surgery in order to halt the deterioration of prognosis in terms of functionality and survival.

The patients who presented without any pathologies showed good post-operative recovery. In those who had associated diseases, over two thirds had improved, a small percentage $(7.5 \%)$ showed no improvement, postoperative deterioration in $4.75 \%$ and deaths in $11.2 \%$.

The average duration of hospital stay was 3.15 days in studies led by Baykan et Coll [28], compared to 18.47 days byTapsoba et Coll [13], Sidibé N [15] had reported similar results with 18.75 days.

Although the duration of stay in our study was lesser than in some African series, it was still considered elevated when compared with reports from Europe, and had a significant link with management of the associated pathologies on admission (P-value $=0)$.

\section{Conclusion}

The impact of co morbid conditions affecting the management of hydrocephalus in the tropical region remains evident. In our context, the most commonly encountered pathologies are anemia, respiratory tract infections, malaria, malnutrition and dehydration. The associated pathology affects the choice of management for each patient, and its impact is felt by the delay in performing the surgery and the post-operative result, as well as functionality and long term prognosis.

A more detailed study targeted on each principal pathology needs to be conducted in view of better analyzing the pathologic link with the development of hydrocephalus in the tropical regions.

\section{Conflict of Interest Statement}

The authors declare that there is no conflict of interest with any financial organization or corporation or individual that can inappropriately influence this work

\section{Abbreviations}

DVP = dérivation ventriculo-peritoneale 
$\mathrm{H} 3 \mathrm{~V}=$ Hydrocéphalie tri ventriculaire

$\mathrm{H} 4 \mathrm{~V}=$ Hydrocéphalie tetra ventriculaire

$\mathrm{H} 2 \mathrm{~V}=$ Hydrocéphalie bi ventriculaire

$\mathrm{VCSb}=$ Ventriculo-cisternostomie (thirt ventriculostomy)

\section{References}

[1] ObamaA, Hydrocéphalie en milieu pédiatrique à Yaoundé, Cameroun, étude de 65 cas. Ann pediatr (Paris), 1994; 4 (41): 249-252.

[2] Tabarki et Coll. Hydrocéphalie de l'enfant, aspects étiologiques et évolutifs à propos de 86 cas observés. Revue Maghreb pédiatrie. mars-avril 2001; 11: 65-70.

[3] Vinchon M, Baroncini M, Delestret I: Adult outcome of pediatric hydrocephalus. Childs NervSyst 2012, [Epub ahead of print].

[4] Smith ER, Butler WE, Barker FG $2^{\text {nd }}$ : In-hospital mortality rates after ventriculoperitoneal shunt procedures in the United States, 1998 to 2000: relation to hospital and surgeon volume of care. J Neurosurg 2004, 100 (Suppl 2): 90-97.

[5] Albright AL, Pollack IF, Adelson PD, Solot JJ: Outcome data and analysis in pediatric neurosurgery. Neurosurgery 1999, 45: 101-106.

[6] Vinchon M. P, P. Dhellemmes. Suivi à l'adulte des patients traites dans l'enfance pour hydrocéphalie Neurochirurgie 54 (2008) 587-596. Sainte Ann Rose. Hydrocéphalie pédiatrique. Paris/1995.

[7] Amrou N. Hydrocéphalies chez les enfants à propos de 63 cas. Thèse de doctorat en médecine Rabat 2003.

[8] Mitangala N. Malnutritionprotéo-énergétique et morbidité liée au paludisme chez les enfants de 0 à 59 mois dans la région de Kivu. République démocratique du Congo. Med Trop 2008; 68: $51-572$.

[9] Topczewska-Lach. Quality of life and psychomotor develppement after surgical treatment of hydrocephalus-eur J pediatrsurg 2005: 15: 2-5.

[10] Guesmi H, Moussa M. Ksira I. Mlaiki A. Krifa H. ArifaN. Hydrocéphalie congénitale: traitement et résultats à long terme à propos de 60 cas. Mag Med 2004, vol. 24 (369): 112-14.

[11] A. Traoré. Les malformations congénitales dans le service de chirurgie générale et pédiatrique de HGT; Thèse de doctorat en Médecine Bamako. 2001-2002 N02-M-66.

[12] BA Momar C., Kpelao E. S., Thioub M., Kouara M., ThiamAlioune B. et coll. Hydrocéphalie post-méningitique chez le nourrisson à Dakar. AJNS. Paans. org/dits/data/2012 Vol 31.

[13] TapsobaT. LAspect épidémiologiques, cliniques et tomodensitométriques des hydrocéphalies chez les enfants de 0 à 15 ans (à propos de 53 patients colligés au centre hospitalier universitaire Yalgado Ouédraogo de Ouagadougou). Médecine Nucléaire 34 S (2010) e3- e7.

[14] Toure S. Résultats a long terme de la dérivation ventriculopéritonéale (a propos de 8 cas). Thèse de Bamako pour l'obtention du doctorat en de médecine, Année 2007-2008.

[15] Sidibé N. Résultats préliminaires de la prise ne charge de l'hydrocéphalie dans le service de chirurgie pédiatrique de l'Hôpital National Donka. Thèse pour l'obtention du Doctorat en Médecine, Année 2012.

[16] Sanoussi S., Kelani A., Chaibou M. S., Baoua M., Assoumane I., Sani R. M., et coll. Les malformations de dandy-walker: aspects diagnostiques et apport de l'endoscopie: a propos de $77 \quad$ casJuly 2013. http://ajns.paans.org/article.php3?id_article $=418 \&$ var_recherc he=hydroc\%E9phalieMasangwi S.J.

[17] OI. S., Di Rocco C. Proposal of evolution theory in the cerebrospinal fluid dynamics and minor pathway hydrocephalus in developing immature brain Child Nerv. System 2006. 22. 662-669.

[18] Dandy W. Experimental hydrocephalus ann. Surg. 1919. 70. 129-142.

[19] BakaliI. Ventriculocisternostomie à propos de 36 cas Thèse de Fès pour l'obtention du doctorat en Médecine $\mathrm{N}^{\circ} 005 / 2010$.

[20] Shuller E. Liquide céphalo-rachidien EMC Neurologie. 1993. 17-028-13. 10-28.

[21] M. L Moutard C. Fallet-blanco. Pathologies neurologiques malformative fotal EMC Pédiatrie. 2004. 210-231.

[22] Labchir N. Prise en charge de l'hydrocéphalie de l'enfant de moins de 15 ans à l'hôpital de Mohammed V de Meknes. Thèse de Casablanca pour l'obtention du doctorat en médecine 2002; 02.

[23] Peudenier S, Dufour T. Les hydrocéphalies de l'enfant 1999, institut mère et enfant, annexe pédiatrique, hôpital du Sud. $\mathrm{http} / /$ www.med.univ/rennes/fr/etude pédiatrie/hydrocephalie.htm

[24] Vincent G. Anatomie du système nerveux central Vol 1; Doin et Cie, Paris 1961, page 611.

[25] Landrieu P., ComoyJ., ZerahM.. Hydrocéphalie de l'enfant EMC Pédiatrie 1988: P 1-10.

[26] Dominique P. Démarche diagnostic devant une anémie chez l'enfant. Corpus médical-faculté de Médecine Grenoble 2004. http//www-sante. UJF -Grenoble.fr/Sante/.

[27] Adjenou K. V., Amadou A. A. ETF ET TDM dans le diagnostic des hydrocéphalies chez l'enfant a Lomé. J. Rech. Sci. Univ. Lomé (Togo), 2012, Série D. 14 (2): 39.

[28] Baycan Ten years of experience with pediatric neuroendoscopic third ventriculostomy Futures and peri operative complication of 210 cases. J. Neurosurg Anesthesiol. 2005. 17 (1). 33-33.

[29] Kanikomo D. Diallo O. Souaré I. S. Diop A A. Maiga Y. Diallo M. Toure AA. Prise en charge de l'hydrocéphalie chez l'enfant à propos de 65 cas enregistrés au CHU Gabriel Toure de Bamako. Journal de Neurologie-Neurochirurgie et Psychiatrie. 2011. 001-N 006. 45 - 51.

[30] Traore I. S. DItinéraire thérapeutique des enfants souffrant d'hydrocéphalie admis à l'hôpital National Donka. Thèse de Conakry pour l'obtention du Doctorat en Médecine. 2012.

[31] Castro- Gago. Benign idiopathic external hydrocephalus in 39 children: it natural history in relation to familial macrocephaly. Neurol 2005. 40 (9). 513-7. 
[32] Sylla A: Etude de l'hydrocéphalie chez l'enfant de 0 à 14 ans dans le service de chirurgie orthopédique et traumatologie du CHU de Gabriel Toure. Thèse de Bamako pour l'obtention du doctorat en médecine. Année 2009.

[33] Zouaghi A. Hydrocéphalie du nouveau-né et du nourrisson (à propos de 78 cas). Thèse pour l'obtention de Doctorat en Médecine de Fés. $2012 \mathrm{~N}^{\circ} 111 / 12$

[34] Musau C. K., Nganga H. N., Mbuthia N. K. Management and functionaloutcome of childhoodhydrocephalusat the Kenyatta national
Nairobihttp://ajns.paans.org/article.php3?id article=468\&var recherche $=$ hydroc $\%$ E9phalie

[35] N'dri O. D., Broalet M. Y. E., Varlet G., Bazeze v. Un cas d'hydrocéphalie chronique de l'adulte par occlusion congénitale de l'ouverture médiane du quatrième ventricule traitée par une foraminotomie et une duroplastie. 2001. ttp://ajns.paans.org/article.php3?id_article $=133 \&$ var_recherch $\mathrm{e}=$ hydroc\%E9phalie 